\title{
Autosomal recessive spastic paraplegia type 14
}

INSERM

\section{Source}

INSERM. (1999). Orphanet: an online rare disease and orphan drug data base. Autosomal recessive spastic paraplegia type 14. ORPHA:100995

Autosomal recessive spastic paraplegia type 14 is a rare, complex hereditary spastic paraplegia characterized by adulthood-onset of slowly progressive spastic paraplegia of lower limbs presenting with spastic gait, hyperreflexia, and mild lower limb hypertonicity associated with mild intellectual disability, visual agnosia, short and long-term memory deficiency and mild distal motor neuropathy. Bilateral pes cavus and extensor plantar responses are also associated. 